\title{
Estabelecimento in vitro e crescimento inicial de Physalis angulata (Solanaceae)
}

\section{Lenaldo Muniz de Oliveira ${ }^{{ }^{*}}$, Anderson de Carvalho Silva ${ }^{1}$, Danilo Marcelo Santos Pereira ${ }^{1}$, Angélica Maria Lucchese $^{2}$ \& José Raniere Ferreira de Santana ${ }^{1}$}

${ }^{1}$ Departamento de Ciências Biológicas e ${ }^{2}$ Departamento de Ciências Exatas, Universidade Estadual de Feira de Santana, Feira de Santana, Bahia, Brasil.

\begin{abstract}
Resumo - O objetivo deste estudo foi estabelecer Physalis angulata in vitro e identificar o meio de cultura mais adequado para a germinação e crescimento inicial da espécie. Nós avaliamos a germinação, o estabelecimento in vitro e o crescimento inicial de suas plântulas em diferentes meios de cultura (MS, WPM e 1/2MS). Primeiro, foram avaliados porcentagem, tempo médio e índice de velocidade de germinação 15 dias após a inoculação das sementes. Em seguida, foram avaliados número médio de raízes e folhas, comprimento da parte aérea e da raiz, e massa seca da parte aérea, foliar e da raiz de plântulas após 15, 30 e 45 dias da inoculação das sementes. A germinação iniciou-se quatro dias após a inoculação e não foi afetada pelos meios de cultura. Por outro lado, foram observadas diferenças significativas entre os tipos de meio de cultura para a maioria dos parâmetros de crescimento avaliados. Os meios de cultura WPM e 1/2MS foram mais adequados para o desenvolvimento inicial das plântulas, sendo recomendados para as demais etapas da micropropagação da espécie.
\end{abstract}

Palavras-chave adicionais: Camapu, micropropagação, meio de cultura, planta medicinal.

\begin{abstract}
In vitro establishment and initial growth of Physalis angulata (Solanaceae)) - The aim of this study was to establish Physalis angulata in vitro and identify the best culture medium for germination and initial growth of the species. We assessed the germination, in

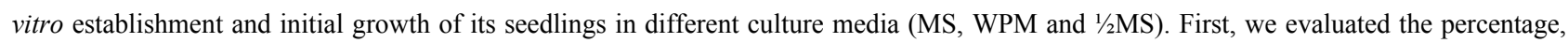
average time and speed index of germination 15 days after seed inoculation. Then, we evaluated the average number of roots and leaves, length of shoots and roots, and dry mass of shoots, leaves and roots of seedlings 15, 30 and 45 days after seed inoculation. Germination started four days after inoculation and the choice of culture media did not affect germination. However, significant differences among culture media were found for most growth parameters evaluated. The culture media WPM and $1 / 2$ MS provide better initial growth of seedlings and these are recommended for the other stages of micropropagation of this species.
\end{abstract}

Additional key words: Camapu, micropropagation, culture medium, medicinal plant.

Physalis angulata L. (Solanaceae) é um pequeno arbusto anual de ampla ocorrência nos Estados Unidos, Americas Central e do Sul e em regiões tropicais no velho mundo (Soares et al. 2009). No Brasil, a espécie é comumente conhecida como camapu, mullaca ou Juá de capote, sendo muito utilizada na medicina popular para o tratamento de doenças como reumatismo crônico, distúrbios renais e do fígado, como sedativo, antifebril, antivomitivo e dermatoses (Souza \& Amorim 2009). Essa prática se deve a presença de derivados esteroidais produzidos e/ou armazenados nas raízes, caules e folhas. Os principais metabólitos produzidos no gênero são conhecidos como fisalinas, esteroides com diversas atividades comprovadas, como imunomoduladora, antimicrobiana, antitumoral, moluscicida, antiparasitária, antiviral e antineoplásica (Tomassini et al. 2000; Lopes et al. 2006).

Quimicamente, as fisalinas são denominadas lactonas sesquiterpênicas esteroidais e são caracterizadas como moléculas de estruturas bastante complexas. Pesquisas realizadas pela Fundação Oswaldo Cruz (Fiocruz) no Rio de Janeiro e em Salvador, têm demonstrado o grande potencial das fisalinas para a produção de anti-iflamatórios com ação

\footnotetext{
*Autor para correspondência: lenaldo.uefs@gmail.com

Editor responsável: Alessandro Rapini

Submetido: 15 abr. 2013; aceito: 10 jul. 2013

Publicação inicial: 30 dez. 2013; versão final: 2 maio 2014
}

até 30 vezes mais potentes que os conhecidos (Tomassini et al. 2000). Apesar do grande potencial dessas substâncias para a indústria farmacêutica, dificuldades para sua produção comercial persistem principalmente devido ao baixo teor em que são encontradas nas plantas. Além disso, as espécies de Physalis apresentam polinização mista, com dominância da polinização cruzada, o que leva à produção de descendentes com elevada variação na produção de metabólitos secundários (Gonzales et al. 2008).

Técnicas de cultura de tecidos, como a micropropagação, têm sido consideradas ferramentas promissoras, tanto para a propagação em larga escala de variedades melhoradas, com maior teor dos compostos bioativos, quanto para a produção in vitro de compostos com alto valor agregado. Como as fisalinas são encontradas em baixas concentrações nos órgãos vegetais, a produção in vitro, via cultivo de células em suspensão, poderá ser uma alternativa viável para contornar o problema da baixa produtividade, como tem sido verificada para outras substâncias de interesse farmacológico (Zhang et al. 2002).

As várias etapas da micropropagação exigem diferentes condições nutricionais e um balanço hormonal adequado. Os meios de cultura se baseiam nas exigências nutricionais das plantas, sendo adequados às necessidades de cada espécie/genótipo e 
fase do cultivo in vitro (Santos-Serejo et al. 2006). Meios de cultura inadequados podem causar sintomas de deficiência nutricional, distúrbios fisiológicos e até a morte dos propágulos (Monteiro et al. 2000). Existe uma grande variedade de meios de cultura adaptados a diversas espécies, diferindo sobretudo na constituição e concentração de nutrientes. Os meios comumente usados são o MS (Murashige \& Skoog 1962) e o WPM (Woody Plant Medium) (Lloyd \& Mccown 1981). Na tentativa de favorecer o crescimento in vitro dos tecidos vegetais, diversos estudos têm proposto a redução na concentração de macro e/ou micronutrientes que compõem esses meios de cultura, suprindo melhor as exigências nutricionais de cada espécie, bem como possibilitando um melhor ajuste osmótico, sobretudo quando o cultivo se inicia a partir da sementes (Villa et al. 2009). Assim, objetivou-se nesta pesquisa a adequação de protocolos de estabelecimento e identificação do melhor meio de cultura para a germinação e crescimento inicial de Physalis angulata.

\section{MATERIAIS E MÉTODOS}

Estabelecimento in vitro. Para o estabelecimento in vitro, foram coletadas sementes de frutos maduros, obtidos de plantas cultivadas na Unidade Experimental Horto Florestal da UEFS. As sementes foram lavadas em água corrente e colocadas para secar sobre papel toalha a temperatura ambiente. Para desinfestação, as sementes foram lavadas em água destilada, seguida da imersão em álcool $70 \%$ por $30 \mathrm{seg}$. e em solução de hipoclorito de sódio ( $\mathrm{NaOCl}$ a 2,5\% de cloro ativo) por 3 min. e, finalmente, lavadas quatro vezes com água destilada autoclavada, segundo a metodologia descrita por Vasconcellos et al. (2003), sendo todas as etapas realizadas em câmara de fluxo laminar.

Após a desinfestação, as sementes foram inoculadas em meio de cultura solidificado com $0,7 \%$ de ágar e suplementado com $3 \%$ de sacarose, com o pH do meio corrigido para 5,7 $\pm 0,1$ antes da autoclavagem. Avaliou-se o efeito de três tipos de meio de cultura: WPM (Lloyd \& Mccown 1981), MS (Murashige \& Skoog 1962) e 1/2MS (com metade da concentração de sais). As sementes foram inoculadas em tubos de ensaios $(12 \times 100 \mathrm{~mm})$, contendo $10 \mathrm{~mL}$ de meio de cultura e mantidas por $15 \mathrm{~d}$ em sala de crescimento a temperatura de $25 \pm 3^{\circ} \mathrm{C}$, fotoperíodo de $16 \mathrm{~h} \mathrm{e}$ radiação fotossintética ativa de $60 \mu \mathrm{mol} \mathrm{m} \mathrm{m}^{-2} \mathrm{~s}^{-1}$. No dia seguinte à inoculação, iniciou-se a avaliação da germinação, conduzida durante $15 \mathrm{~d}$. Avaliou-se a porcentagem de germinação $(\mathrm{G})$, tempo médio de germinação (TMG) e o índice de velocidade de germinação (IVG).

$\mathrm{O}$ delineamento experimental foi inteiramente casualizado (DIC), com quatro repetições por tratamento, sendo cada repetição constituída de 25 tubos com uma semente cada, totalizando 100 sementes por tratamento. A porcentagem de germinação foi calculada pela fórmula proposta nas Regras para Análise de Sementes (BRASIL 1992); o tempo médio de germinação foi obtido através de contagens diárias das sementes germinadas até o $15^{\circ}$ dia e calculado através da metodologia sugerida por Labouriau (1983), sendo os resultados expressos em dias; o índice de velocidade de germinação foi calculado pelo somatório do número de sementes germinadas a cada dia, dividido pelo número de dias decorridos entre a semeadura e a germinação, de acordo com a fórmula de Maguire (1962).

Os resultados obtidos foram submetidos à análise de variância e as médias comparadas pelo teste de Tukey a $5 \%$ de probabilidade, utilizando o software SISVAR, versão 5.3 (Ferreira 2011).

Crescimento inicial. Para avaliar o efeito do meio de cultura sobre o crescimento inicial da espécie, um novo experimento foi realizado. As sementes foram desinfestadas e inoculadas nos três diferentes meios de cultura (WPM, MS e 1/2MS), conforme os procedimentos e as condições descritos acima. Após 15,30 e 45 dias de cultivo in vitro quantificou-se o número médio de raízes $(\mathrm{NR})$ e de folhas $(\mathrm{NF})$, comprimento da parte aérea (CPA) e da maior raiz (CR), e massa seca da parte aérea (MSPA), foliar (MSF) e da raiz (MSR) das plântulas.

$\mathrm{O}$ experimento foi conduzido em delineamento inteiramente casualizado (DIC), com quatro repetições, sendo cada repetição constituída de cinco tubos, com uma planta por tubo, totalizando 20 plântulas por tratamento para cada período de avaliação. Os resultados foram, então, submetidos às mesmas análises do experimento anterior.

\section{RESUltados}

Estabelecimento in vitro. $\mathrm{O}$ protocolo para assepsia utilizado foi eficiente, não havendo registro de contaminação nas unidades experimentais. De modo semelhante, não foi verificado oxidação dos meios de cultura e eles se mantiveram translúcidos em todos os tratamentos. A germinação iniciou-se quatro dias após a inoculação in vitro, sendo detectadas diferenças significativas entre os resultados obtidos apenas para o tempo médio de germinação (TMG) nos diferentes meios de cultura. Contudo, não foram detectadas diferenças significativas para a porcentagem de germinação $(G)$ e índice de velocidade de germinação (IVG) (Tabela 1).

Crescimento inicial. A avaliação das plântulas após 15 dias de cultivo nos diferentes meios de cultura demonstrou não haver diferenças significativas entre os resultados obtidos para as variáveis número de raízes por brotação (NR), massa seca de folhas (MSF) e de raízes (MSR) (Tabela 2). Por outro lado, para o número 
Tabela 1. Porcentagem de germinação, tempo médio de germinação (TMG) e índice de velocidade de germinação (IVG) das sementes de Physalis angulata inoculadas em diferentes meios de cultura. CV- coeficiente de variação. Feira de Santana, Bahia, 2013.

\begin{tabular}{llll}
\hline $\begin{array}{c}\text { Meio de } \\
\text { cultura }\end{array}$ & Germinação (\%) & $\begin{array}{c}\text { TMG } \\
\text { (dias) }\end{array}$ & IVG \\
\hline MS & $80^{\mathrm{a}}$ & $2,7^{\mathrm{a}}$ & $7,0^{\mathrm{a}}$ \\
$1 / 2 \mathrm{MS}$ & $82^{\mathrm{a}}$ & $3,1^{\mathrm{ab}}$ & $7,8^{\mathrm{a}}$ \\
$\mathrm{WPM}$ & $89^{\mathrm{a}}$ & $3,5^{\mathrm{b}}$ & $7,7^{\mathrm{a}}$ \\
\hline $\mathrm{CV}(\%)$ & 8,16 & 10,68 & 10,16 \\
\hline
\end{tabular}

Médias seguidas de mesma letra na coluna não diferem significativamente entre si pelo teste de Tukey ao nível de $5 \%$ de probabilidade.

de folhas por planta (NF) e comprimento da maior raiz (CR) obteve-se maior valor para as plântulas cultivadas em meio WPM (Tabela 2), enquanto que, para o comprimento da parte aérea (CPA) e massa seca da parte aérea (MSPA), os maiores valores foram obtidos em plantas cultivadas em meio WPM e $1 / 2 \mathrm{MS}$, não havendo diferenças significativas entre os mesmos (Tabela 2).

$\mathrm{Na}$ avaliação realizada após 30 dias de cultivo, verificou-se que o número de raízes e de folhas por brotação foi maior nas plântulas cultivadas em meio $1 / 2 \mathrm{MS}$, assim como o comprimento e a massa seca da parte aérea (Tabela 3). Já para comprimento de raiz, os melhores resultados foram encontrados nas plântulas cultivadas em meio MS.

Após 45 dias de cultivo, verificou-se que as variáveis número de raízes, comprimento e massa seca da parte aérea atingiram maiores valores em plantas cultivadas nos meios WPM e 1/2MS. O número de folhas por brotação variou positivamente para as plântulas cultivadas em meio WPM. Já para a massa seca de folhas e de raízes, diferenças significativas não foram detectadas (Tabela 4).

\section{DISCUSSÃo}

Estabelecimento in vitro. Os resultados demonstram que as variações nos níveis salinos do meio de cultura, em função da concentração de minerais nos diferentes meios, não comprometeram a germinabilidade das sementes de Physalis angulata. Eles apontam ainda para a adaptabilidade da espécie a ambientes salinos, tendo em vista que a taxa de germinação e o IVG não foram afetados pelas diferenças nas concentrações salinas dos meios e que, apesar dos diferentes meios de cultura terem afetado o TMG, estes não prejudicaram a qualidade das plântulas obtidas. A taxa de germinação parece ser bem variável entre as espécies de Physalis. Chaves et al. (2005) trabalhando com a espécie Physalis peruviana L. obteve taxa de germinação das sementes abaixo dos $30 \%$ quando colocadas em meio $\mathrm{MS}^{3 / 4}$ utilizando diferentes métodos de desinfestação. Souza et al. (2011), trabalhando com estresse salino de sementes de Physalis angulata verificaram uma significativa resistência à salinidade dessa espécie, com IVG para as sementes osmocondicionadas semelhante ao obtido em sementes não osmocondicionadas, até a concentração salina com CE $10 \mathrm{dS} \mathrm{m}^{-1}$. Contudo, trabalhos com outras espécies têm demonstrado que uma adequada embebição das sementes é dependente da concentração de sais e outros compostos osmoticamente ativos no meio.

Crescimento inicial. Para Drapeu et al. (1986), a composição do meio de cultura, formada por macro e micronutrientes, além de compostos orgânicos, apresenta grande influência no crescimento das plantas in vitro. Portanto, ao se iniciar um processo biotecnológico com células vegetais, deve-se, em primeira instância, estabelecer o meio adequado para o seu cultivo.

O tipo de formulação mineral mais adequado para o cultivo de diversas espécies vegetais tem variado bastante, mesmo entre espécies com hábitos semelhantes. O meio de cultura MS e suas variações destacam-se como sendo os mais utilizados em cultura de tecidos vegetais para a maioria das espécies herbáceas (Bertozzo \& Machado 2010). Já o meio WPM, que apresenta $25 \%$ das concentrações de íons nitrato e amônia do meio em relação ao meio MS, tem sido empregado com êxito para a maioria das espécies lenhosas.

Ledo et al. (2007), pesquisando a ação de meios sobre a cultura da mangabeira (Hancornia speciosa Gomes), obtiveram melhor desenvolvimento das

Tabela 2. Número médio de raízes (NR), número médio de folhas (NF), comprimento da parte aérea (CPA), comprimento da raiz (CR), massa seca da parte aérea (MSPA), massa seca foliar (MSF) e massa seca da raiz (MSR) de Physalis angulata após 15 dias de cultivo in vitro em diferentes meios de cultura. CV- coeficiente de variação. Feira de Santana, Bahia, 2013.

\begin{tabular}{llllllll}
\hline $\begin{array}{l}\text { Meio de } \\
\text { Cultura }\end{array}$ & NR & NF & CPA (cm) & CR (cm) & MSPA (g) & MSF (g) & MSR (g) \\
\hline MS & $9,12^{\mathrm{a}}$ & $4,31^{\mathrm{b}}$ & $3,82^{\mathrm{b}}$ & $6,83^{\mathrm{b}}$ & $0,0016^{\mathrm{b}}$ & $0,0049^{\mathrm{a}}$ & $0,0019^{\mathrm{a}}$ \\
$1 / 2 \mathrm{MS}$ & $11,25^{\mathrm{a}}$ & $4,37^{\mathrm{b}}$ & $6,56^{\mathrm{a}}$ & $6,25^{\mathrm{b}}$ & $0,0040^{\mathrm{a}}$ & $0,0086^{\mathrm{a}}$ & $0,0011^{\mathrm{a}}$ \\
WPM & $12,12^{\mathrm{a}}$ & $5,00^{\mathrm{a}}$ & $6,88^{\mathrm{a}}$ & $7,48^{\mathrm{a}}$ & $0,0047^{\mathrm{a}}$ & $0,0066^{\mathrm{a}}$ & $0,0020^{\mathrm{a}}$ \\
\hline CV $(\%)$ & 33,15 & 12,73 & 13,10 & 13,09 & 20,41 & 24,18 & 29,58 \\
\hline
\end{tabular}

Médias seguidas de mesma letra na coluna não diferem significativamente entre si pelo teste de Tukey ao nível de 5\% de probabilidade. 
Tabela 3. Número médio de raízes (NR), número médio de folhas (NF), comprimento da parte aérea (CPA), comprimento da raiz (CR), massa seca da parte aérea (MSPA), massa seca foliar (MSF) e massa seca da raiz (MSR) de Physalis angulata após 30 dias de cultivo in vitro em diferentes meios de cultura. CV- coeficiente de variação. Feira de Santana, Bahia, 2013.

\begin{tabular}{llllllll}
\hline $\begin{array}{l}\text { Meio de } \\
\text { Cultura }\end{array}$ & NR & NF & CPA $(\mathrm{cm})$ & CR $(\mathrm{cm})$ & MSPA (g) & MSF (g) & MSR (g) \\
\hline MS & $7,69^{\mathrm{b}}$ & $4,94^{\mathrm{b}}$ & $5,00^{\mathrm{b}}$ & $11,0^{\mathrm{a}}$ & $0,003^{\mathrm{b}}$ & $0,008^{\mathrm{b}}$ & $0,002^{\mathrm{a}}$ \\
1/2MS & $12,3^{\mathrm{a}}$ & $7,36^{\mathrm{a}}$ & $12,4^{\mathrm{a}}$ & $7,15^{\mathrm{b}}$ & $0,016^{\mathrm{a}}$ & $0,016^{\mathrm{a}}$ & $0,002^{\mathrm{a}}$ \\
WPM & $7,69^{\mathrm{b}}$ & $4,88^{\mathrm{b}}$ & $6,85^{\mathrm{b}}$ & $7,94^{\mathrm{b}}$ & $0,005^{\mathrm{b}}$ & $0,005^{\mathrm{b}}$ & $0,001^{\mathrm{a}}$ \\
\hline CV $(\%)$ & 33,88 & 21,53 & 15,88 & 22,50 & 18,54 & 14,92 & 31,29 \\
\hline
\end{tabular}

Médias seguidas de mesma letra na coluna não diferem significativamente entre si pelo teste de Tukey ao nível de $5 \%$ de probabilidade.

Tabela 4. Número médio de raízes (NR), número médio de folhas (NF), comprimento da parte aérea (CPA), comprimento da raiz (CR), massa seca da parte aérea (MSPA), massa seca foliar (MSF) e massa seca da raiz (MSR) de Physalis angulata após 45 dias de cultivo in vitro em diferentes meios de cultura. CV- coeficiente de variação. Feira de Santana, Bahia, 2013.

\begin{tabular}{llllllll}
\hline $\begin{array}{l}\text { Meio de } \\
\text { Cultura }\end{array}$ & NR & NF & CPA $(\mathrm{cm})$ & CR $(\mathrm{cm})$ & MSPA $(\mathrm{g})$ & MSF $(\mathrm{g})$ & MSR $(\mathrm{g})$ \\
\hline MS & $6,44^{\mathrm{b}}$ & $7,63^{\mathrm{b}}$ & $5,35^{\mathrm{c}}$ & $11,7^{\mathrm{a}}$ & $0,007^{\mathrm{b}}$ & $0,014^{\mathrm{a}}$ & $0,002^{\mathrm{a}}$ \\
1/2MS & $10,1^{\mathrm{a}}$ & $7,49^{\mathrm{b}}$ & $12,3^{\mathrm{b}}$ & $8,57^{\mathrm{b}}$ & $0,020^{\mathrm{a}}$ & $0,016^{\mathrm{a}}$ & $0,001^{\mathrm{a}}$ \\
WPM & $11,6^{\mathrm{a}}$ & $9,06^{\mathrm{a}}$ & $13,9^{\mathrm{a}}$ & $13,1^{\mathrm{a}}$ & $0,027^{\mathrm{a}}$ & $0,018^{\mathrm{a}}$ & $0,004^{\mathrm{a}}$ \\
\hline CV $(\%)$ & 30,40 & 18,91 & 19,82 & 39,69 & 42,12 & 14,58 & 74,81 \\
\hline
\end{tabular}

Médias seguidas de mesma letra na coluna não diferem significativamente entre si pelo teste de Tukey ao nível de $5 \%$ de probabilidade.

raízes nas plântulas cultivadas em meio 1/2MS. Já Leitzke et al. (2009) identificaram melhor enraizamento em plântulas de amoreira-preta (Rubus fruticosus L.) quando cultivada em meio WPM. Para o abacaxizeiro [Ananas comosus (L.) Merr.], valores equivalentes de massa seca das raízes foram registrados em plântulas cultivadas em meio MS e $1 / 2$ MS (Tamaki et al. 2007). Por outro lado, a menta $($ Menta $\times$ piperita $\mathrm{L}$.) desenvolveu-se melhor quando cultivada em meio MS (Tonietto et al. 2008). O mesmo foi registrado para Orthophytum mucugense Wand. \& A.A.Conc., na qual plântulas cultivadas em meios MS apresentaram maiores ganhos de massa seca (Bellintani et al. 2007). Esses resultados reforçam a idéia de que as respostas de crescimento em função da concentração de sais no meio de cultura são altamente relacionadas às exigências nutricionais, típicas de cada espécie e fase do cultivo.

A análise de crescimento de Physalis angulata ao longo dos 45 dias de cultivo in vitro demonstrou que maiores taxas de crescimento podem ser obtidas com a utilização do meio de cultura WPM e 1/2MS, sobretudo em relação ao comprimento da parte aérea e acúmulo de massa seca na parte aérea (Tabelas 2-4). Essas variáveis são parâmetros importantes para o cultivo in vitro, pois permitem a obtenção de mais explantes para o próximo ciclo de micropropagação e, consequentemente, maior taxa de multiplicação. Assim, a escolha do melhor meio de cultura é essencial no processo de micropropagação, visto que, além de fornecer os nutrientes necessários, possibilita melhor crescimento das plântulas in vitro (Caldas et al. 1998).

Rodrigues et al. (2013), avaliando diferentes concentrações de sais do meio MS $(0,25,50,75$ e
$100 \%$ no cultivo in vitro de Physalis peruviana, identificou o meio com $50 \%$ dos sais como o mais eficiente para a multiplicação in vitro da espécie, utilizando suplementação de $1,3 \quad \mathrm{mg}^{-1} \quad \mathrm{~L}^{-1}$ de 6-benzilaminopurina. Por outro lado, quando o meio não foi suplementado com esse regulador de crescimento, o meio composto por $75 \%$ dos sais MS promoveu as melhores respostas. Ambas as respostas corroboram os resultados obtidos neste trabalho com Physalis angulata, com as maiores taxas de crescimento em meios menos concentrados.

Em suma, os resultados obtidos aqui demonstram que os diferentes meios de cultura testados não afetam os parâmetros de germinação in vitro das sementes de Physalis angulata e que os meios de cultura com menor concentração salina (WPM e 1/2MS) permitem melhor desenvolvimento inicial das plântulas e devem ser utilizados nas demais etapas da micropropagação dessa espécie.

\section{AGRADECIMENTOS}

Os autores agradecem o financiamento da FAPESB, CAPES e CNPq.

\section{REFERÊNCIAS}

Bellintani, C.M.; Lima, C.C.; Brito, L.A.; Santana, F.R.J. \& Dornelles, C.L.A. 2007. Estabelecimento in vitro de Orthophytum mucugense e Neoregelia mucugensis. bromélias endêmicas da Chapada Diamantina. Bahia - Brasil. Revista Brasileira de Biociências 5: 1101-1103. 
Bertozzo, F. \& Machado, I.S. 2010. Meios de cultura no desenvolvimento de ápices caulinares de mamoneira (Ricinus communis L.) in vitro. Ciência e Agrotecnologia 34(6): $1477-$ 1482.

BRASIL 1992. Regras para Análise de Sementes. Ministério da Agricultura, Secretaria Nacional de Defesa da Agropecuária, Brasilia.

Caldas, L.S.; Haridasan, P. \& Ferreira, M.E. 1998. Meios Nutritivos. In: A.C. Torres, L.S. Caldas \& J.A. Buso (Orgs), Cultura de Tecidos e Transformação Genética de Plantas. EMBRAPA-SPI/EMBRAPA-CNPH, Brasilia, p. 87-132.

Chaves, A.C.; Schuch, M.W. \& Erig, A.C. 2005. Estabelecimento e multiplicação in vitro de Physalis peruviana L. Ciência e Agrotecnologia 29(6): 1281-1287.

Drapeau, D.; Blanch, H.W. \& Wilke, C.R. 1986. Growth kinetics of Dioscorea deltoidea and Catharanthus roseus in batch culture. Bioengineering and Biotechnology 28: 1555-1563.

Ferreira, D. F. 2011. Sisvar: a computer statistical analysis system. Ciência e Agrotecnologia 35(6): 1039-1042.

Gonzales, O.T.; Torres, J.M.C.; Cano, C.I.M.; Arias, M.L. \& Arboleda, A.A.N. 2008. Caracterización morfológica de cuarenta y seis accesiones de Uchuva (Physalis peruviana L.), em Antioquia (Colombia). Revista Brasileira de Fruticultura 30(3): 708-715.

Labouriau, L.G. 1983. A Germinação das Sementes. OEA, Washington.

Lédo, A.S.; Seca, G.S.V.; Barboza, S.B.S.C. \& Silva, J.J.F. 2007. Crescimento inicial de mangabeira (Hancornia speciosa Gomes) em diferentes meios de germinação in vitro. Ciência e Agrotecnologia. 31(4): 989-993.

Leitzke, L.N.; Damiani, C.R. \& Schuch, M.W. 2009. Meio de cultura, concentração de AIB e tempo de cultivo no enraizamento in vitro de amoreira-preta e framboeseira. Revista Brasileira de Fruticultura 31(2): 582-587.

Lloyd, G. \& Mccown, B. 1981. Commercially feasible micropropagation of montain laurel, Kalmia latifolia, by use of shoot tip culture. Combined Proceedings of the International Plant Propagator's Society 30: 421-327.

Lopes, D.C.D.X.P.; Freitas, Z.M.F.; Santos, E.P. \& Tomassini, T.C.B. 2006. Atividade antimicrobiana e fototóxica de extratos de frutos e raízes de Physalis angulata L. Revista Brasileira de Farmacognosia 16(2): 206-210.

Maguire, J.D. 1962. Speed of germination aid in selection and evaluation of seedling emergence and vigor. Crop Science 2(1): 176-177.

Monteiro, A.C.B.A.; Higashi, E.N.; Gonçalves, A.N. \& Rodriguez, A.P.M. 2000. A novel approach for the definition of the inorganic medium components for micropropagation of yellow passion fruit (Passiflora edulis Sims f. flavicarpa Deg.). In vitro Cellular and Developmental Biology-plant 36(6): 527531.

Murashige, T. \& Skoog, F.A. 1962. A revised medium for rapid growth and bioassay with tobacco tissue culture. Phisiologia Plantarum 15: 473-497.

Rodrigues, F.A.; Penoni E.S.; Soares, J.D.R. \& Pasqual, M. 2013. Diferentes concentrações de sais do meio MS e BAP na mutiplicação in vitro de Physalis peruviana L. Bioscience Journal 29(1): 77-82.

Santos-Serejo, J.A.; Junghans, T.G.; Soares, T.L. \& Silva, K.M. 2006. Meios nutritivos para micropropagação de plantas. In: A.S. Sousa \& T.G. Junghans (eds.), Introdução à Micropropagação de Plantas. Embrapa Mandioca e Fruticultura Tropical, Cruz das Almas, p. 79-98.

Soares, E.L.C.; Vendruscollo, G.S.; Vignoli-Silva, M.; Thode, V.A.; Silva, J.G. \& Mentz, L.A. 2009. O gênero Physalis L. (Solanaceae) no Rio Grande do Sul, Brasil. Pesquisas, Botânica 60: $323-340$.

Souza, N.K.R. \& Amorim, S.M.C. 2009. Crescimento e desenvolvimento de Physalis angulata Lineu submetida ao déficit hídrico. Revista Acadêmica 7(1): 65-72.

Souza, M.O.; Souza, C.L.M. \& Pelacani, C.R. 2011. Germinação de sementes osmocondicionadas e não-osmocondicionadas e crescimento inicial de Physallis angulata L. (Solanaceae) em ambientes salinos. Acta Botanica Brasilica 25(1): 105-112.

Tamaki, V.; Mercier, H. \& Nievola, C.C. 2007. Cultivo in vitro de clones de Ananas comosus (L.) Merril cultivar 'Smooth Cayenne' em diferentes concentrações de macronutrientes. Hoehnea 34: 69-73.

Tomassini, T.C.B.; Barbi, N.S.; Ribeiro, I.M. \& Xavier, D.C.D. 2000. Gênero Physalis - uma revisão sobre vitaesteróides. Química Nova 23(1): 47-57.

Tonietto, S.M.; Perini, C.B. \& Tonietto, A. 2008. Concentracões e composicão do meio de Murashige \& Skoog na micropropagacão da Menta. Plant Cell Culture Micropropagation 4(1): 42-47.

Vasconcellos, A.G.; Lage, C.L.S. \& Esquibel, M.A. 2003. In vitro flowering of Physalis angulata L. (Solanaceae). Revista Brasileira de Plantas Medicinais 6(1): 23-27.

Villa, F.; Pasqual, M.; Assis, F.A.; Assis, G.A. \& Zárraga, D.Z.A. 2009. Micropropaagação de duas espécies frutíferas, em meio de cultura DSD1, modificado com fontes de boro e zinco. Ciência e Agrotecnologia 33(2): 468-472.

Zhang, W.; Curtin, C.; Kikuchi, M. \& Franco, C. 2002. Integration of jasmonic acid and light irradiation for enhancement of anthocyanin biosynthesis in Vitis vinifera suspension cultures. Plant Science 162: 459-468. 